\title{
Desempenho de cultivares de mandioca em ambiente subtropical
}

\author{
Luana Fernandes Tironi; Lilian Osmari Uhlmann; Nereu Augusto Streck (*); \\ Flávia Kaufmann Samboranha; Charles Patrick de Oliveira de Freitas; Michel Rocha da Silva
}

Universidade Federal de Santa Maria (UFSM), Departamento de Fitotecnia, Av. Roraima, 1.000, 97105-900

Santa Maria (RS), Brasil.

(*) Autor correspondente: nstreck2@yahoo.com.br

Recebido: 7/out./2014; Aceito: 30/nov./2014

\section{Resumo}

O objetivo deste trabalho foi avaliar e comparar as variáveis de crescimento, o desenvolvimento e os componentes de produtividade de raízes e hastes de cinco cultivares de mandioca em ambiente subtropical no Rio Grande do Sul, Brasil. O experimento de campo foi conduzido nos anos agrícolas de 2010-2011 e 2011-2012, em Santa Maria, RS, com cinco cultivares de mandioca (Fepagro-RS13, Fepagro-RS14, Estrangeira, Fécula Branca e Cascuda) no delineamento blocos ao acaso com quatro repetições em esquema bifatorial. Foram coletadas variáveis de crescimento e desenvolvimento como área foliar, altura de plantas e número de folhas e componentes de produtividade de raízes e hastes. As cultivares Fepagro-RS13 e Fepagro-RS14 possuem maior IAF com elevada produção de parte aérea e maior altura total comparadas às das cultivares Estrangeira, Fécula Branca e Cascuda por emitirem maior quantidade de ramificações simpodiais. As cultivares Fepagro-RS13 e Fepagro-RS14 possuem elevada produção tanto de parte aérea quanto de raiz, enquanto as cultivares Estrangeira, Cascuda e Fécula Branca possuem maior aptidão para produção de raízes tuberosas em ambiente subtropical no Rio Grande do Sul, Brasil.

Palavras-chave: Manihot esculenta Crantz, desenvolvimento, raízes tuberosas, hastes, componentes de produtividade.

\section{Performance of cassava cultivars in subtropical environment}

\begin{abstract}
The objective of this study was to evaluate and compare variables of growth, development and yield components of roots and stems of five cassava cultivars in subtropical environment in Rio Grande do Sul, Brazil. A field experiment was conducted in the 2010-2011 and 2011-2012 growing seasons at Santa Maria, RS, with five cassava cultivars, Fepagro - RS 13, Fepagro - RS 13, Fepagro - RS 14, Estrangeira, Fécula Branca and Cascuda in a randomized block design with four replicates and a two factor scheme. Variables of growth and development such as leaf area, plant height and leaf number and yield components of roots and stems were collected. The cultivars Fepagro - RS 13 and Fepagro - RS 14 have the highest LAl, above-ground biomass and height compared to the cultivars Estrangeira, Fécula Branca and Cascuda, because the former have greater sympodial branching. Cultivars Fepagro - RS13 and Fepagro - RS 14 have high production of both above-ground and tuber roots whereas cultivars Estrangeira, Cascuda and Fécula Branca are adapted for tuber roots production in subtropical environment of Rio Grande do Sul, Brazil.
\end{abstract}

Key words: Manihot esculenta Crantz, development, tuber roots, stems, yield components.

\section{INTRODUÇÃO}

A mandioca (Manihot esculenta Crantz) é uma cultura importante a nível mundial devido a sua boa adaptabilidade a diversos ambientes, rusticidade e baixa exigência de fertilidade do solo (Alves, 2002), o que a torna a terceira maior fonte de alimento nas regióes tropicais, após o arroz e o milho (FAOSTAT, 2014). Por isso ela está presente na maioria das pequenas propriedades familiares gaúchas, sendo uma fonte de carboidratos para alimentação humana e animal de menor custo (Schons et al., 2009). O Brasil é o quarto maior produtor mundial, atrás da Nigéria, Tailândia e Indonésia (FAOSTAT, 2014). Na safra de 2014 foram colhidos $23.439 .614 \mathrm{t}$ de raízes numa área de 1.592.091 ha, com uma produtividade média de $14.723 \mathrm{t} \mathrm{ha}^{-1}$ (IBGE, 2014), bem abaixo do potencial produtivo, que pode chegar até $60 \mathrm{t} \mathrm{ha}^{-1}$ (Cock, 1990). O Estado do Pará é o maior produtor nacional, com 4.797.542 t, seguido do Paraná, com 4.075.605 t, da Bahia, com 2.087.523 t, do Maranhão, com 1.631.860, 
de Sáo Paulo, com 1.308.286, e do Rio Grande do Sul, que na safra de 2014 produziu 1.190.523 t (IBGE, 2014).

A parte mais importante da planta é a raiz, rica em fécula, utilizada tanto na alimentação humana e animal quanto como matéria-prima para diversas indústrias. A mandioca classificada como de mesa na sua maioria é comercializada in natura, mas a comercialização da mandioca pré-cozida e congelada está aumentando. A mandioca classificada para indústria tem uma variedade de usos, dos quais a farinha e a fécula são as mais importantes. A parte aérea pode ser utilizada na alimentação animal, na qual as folhas e hastes são utilizadas na forma de silagem, feno, ou mesmo frescas, e também na alimentaçáo humana, na preparação de alimentos típicos das regióes Norte e Nordeste do Brasil (Cardoso et al., 2006).

A estrutura morfológica da planta de mandioca pode diferir de acordo com o genótipo. Alguns apresentam o caule ereto (monopodial), enquanto outros possuem caule ramificado com inflorescência (simpódio) com duas, três ou quatro hastes, denominadas ramificaçôes simpodiais (Carvalho \& Fukuda, 2006), e essas diferenças morfológicas podem interferir na relaçáo fonte-dreno da planta e refletir em diferenças no crescimento e desenvolvimento de diferentes cultivares de mandioca.

No Rio Grande do Sul já foram realizados alguns trabalhos de caracterização agronômica de cultivares de mandioca (Chielle et al., 2007; 2009; Morales et al., 2009) nos quais foram avaliadas algumas variáveis de produtividade de raízes e de parte aérea e também a altura de plantas. Além dessas variáveis, é importante também a caracterização de variáveis mais básicas do crescimento e do desenvolvimento, principalmente o crescimento e desenvolvimento foliar, uma vez que essas duas variáveis definem a evolução do índice de área foliar que intercepta radiação solar ao longo da estação de crescimento para fotossíntese e produção de fotoassimilados que serão usados para acumulação de amido nas raízes. Dentre essas variáveis, uma variável de desenvolvimento foliar geralmente quantificada é o filocrono, que é o intervalo de tempo entre o aparecimento de duas folhas sucessivas na haste de uma planta (Wilhelm \& McMaster, 1995), e uma variável de crescimento importante é o índice de área foliar (IAF). Além disso, essas variáveis de crescimento e desenvolvimento são importantes em outras aplicaçôes como, por exemplo, para a calibração de novas cultivares em modelos agrícolas baseados em processos, como o modelo de mandioca GUMCAS modificado (Gabriel et al., 2014).

Assim, o objetivo deste trabalho foi avaliar e comparar variáveis de crescimento e desenvolvimento e os componentes de produtividade de raízes e hastes de cinco cultivares de mandioca em ambiente subtropical no Rio Grande do Sul, Brasil.

\section{MATERIAL E MÉTODOS}

O estudo foi realizado em Santa Maria, RS (latitude: 29043'S, longitude: 534' W e altitude de $95 \mathrm{~m}$ ). O clima da regiâo, segundo a classificação de Köppen, é Cfa - subtropical úmido com verôes quentes, sem estação seca definida.

O experimento de campo foi conduzido em dois anos agrícolas, 2010-2011 e 2011-2012, com cinco cultivares de mandioca (Fepagro-RS13, Fepagro-RS14, Estrangeira, Cascuda e Fécula Branca), as quais diferem na classificação quanto a finalidade de uso, ramificação e morfologia de folhas, haste e raízes (Tabela 1). Algumas plantas das cultivares Estrangeira e Fécula Branca apresentaram ramificação no final da estação de crescimento, mas para padronização assumiu-se que essas cultivares de forma geral não ramificam (Tabela 1).

O delineamento experimental foi o de blocos ao acaso com quatro repetiçôes em esquema bifatorial $5 \times 2$ (cinco cultivares e dois anos agrícolas). A densidade de plantas de mandioca foi de 15.625 plantas/ha, no espaçamento de $0,8 \mathrm{~m} \times 0,8 \mathrm{~m}$, e cada repetiçáo foi uma parcela de cinco fileiras de $9 \mathrm{~m}$ de comprimento.

O preparo do solo foi realizado de forma convencional e a adubação seguiu a recomendação técnica para a cultura da mandioca, realizada a partir de análise de solo (CQFSRS, 2004). O plantio foi realizado nos dias 6 de outubro de 2010 (primeiro ano agrícola) e no dia 27 de setembro de 2011 (segundo ano agrícola). A colheita, nos dois anos agrícolas, foi realizada ao final de um ciclo de crescimento das plantas, nos dias 15 de junho de 2011 (primeiro ano agrícola) e 20 de junho de 2012 (segundo ano agrícola).

Foi determinada a data de emergência, considerada quando $50 \%$ das plantas encontravam-se visíveis na superfície do solo, e foram selecionadas aleatoriamente seis

Tabela 1. Classificação quanto ao uso, ramificação e morfologia de folhas, hastes e raízes das cinco cultivares de mandiocas usadas no estudo

\begin{tabular}{|ccccccc}
\hline Característica & Fepagro-RS13 & Fepagro-RS14 & Cascuda & \multicolumn{2}{c}{ Estrangeira } & Fécula Branca \\
\hline Uso & Forrageira & Forrageira & Mesa & Mesa & Indústria \\
\hline Ramificação & Dico-tricotômica & Dico-tricotômica & Dico-quatricotômica & - & - \\
\hline N. de lóbulos na folha & $6-7$ & $6-7$ & $7-9$ & $7-9$ & Vermelha \\
\hline $\begin{array}{c}\text { Coloração do pecíolo } \\
\text { Coloração da haste }\end{array}$ & Verde & Verde & Vermelha & Rosada & Verde-prata \\
\hline $\begin{array}{c}\text { Coloração da película } \\
\text { das raízes }\end{array}$ & Marrom-clara & Marrom-clara & Marrom-escura & Marrom-escura & Branca \\
\hline
\end{tabular}


plantas (três em cada linha central) de cada parcela, as quais foram marcadas com arame colorido uma semana após a emergência. Nas plantas marcadas foi contado o número de folhas semanalmente, sendo considerada folha visível aquela cujas bordas de pelo menos um dos lóbulos não se tocavam mais (Schons et al., 2007), e em uma planta marcada em cada parcela foi medido quinzenalmente o comprimento do maior lóbulo de cada folha, para cálculo da área foliar, e contado o número de folhas senescidas. A área de cada folha ( $\mathrm{cm}^{2} /$ folha) foi estimada a partir do comprimento do maior lóbulo $(\mathrm{cm})$ pela equação $\mathrm{y}=\mathrm{ax}$, em que "a" e "b" são coeficientes, y é a área foliar $\left(\mathrm{cm}^{2}\right)$ e x o comprimento do maior lóbulo $(\mathrm{cm})$. Para a estimativa da equação foram utilizadas aproximadamente 50 folhas de cada cultivar, nas quais mediu-se o comprimento do maior lóbulo e estimou-se a área, com o programa Quant. Com esses dados realizou-se uma regressão não linear para estimativa dos coeficientes "a" e "b", utilizando-se o aplicativo Excel. O índice de área foliar (IAF) foi calculado dividindo-se a soma das áreas individuais das folhas pela área de solo ocupada por uma planta $\left(0,64 \mathrm{~m}^{2}\right)$.

Os valores de soma térmica diária $\left(\mathrm{STd},{ }^{\circ} \mathrm{C}\right.$ dia) foram calculados usando-se dados diários de temperatura mínima e máxima do ar coletados na Estação Climatológica Principal da UFSM, localizada a aproximadamente $150 \mathrm{~m}$ da área experimental, através da fórmula:

$\mathrm{STd}=(\mathrm{Tm}-\mathrm{Tb}) .1 \mathrm{dia}$

em que Tm é a temperatura média diária do ar $\left({ }^{\circ} \mathrm{C}\right)$ e $\mathrm{Tb}$, a temperatura base para a cultura $\left({ }^{\circ} \mathrm{C}\right)$, considerada como $14^{\circ} \mathrm{C}$ (Schons et al., 2007). A soma térmica acumulada a partir da emergência ou da data média de ocorrência das ramificaçóes simpodiais $\left(\mathrm{STa},{ }^{\circ} \mathrm{C}\right.$ dia), foi calculada por:

$\mathrm{STa}=\sum \mathrm{STd}$

sendo $\sum S T$ d o somatório das somas térmicas diárias.

O filocrono $\left({ }^{\circ} \mathrm{C}\right.$ dia folha $\left.{ }^{-1}\right)$ para a haste principal (HP) e para as ramificaçôes simpodiais RS1 e RS2 foi estimado como o inverso do coeficiente angular da regressão linear simples entre NF e STa, a partir da emergência da cultura. Para a determinaçáo do filocrono na haste principal, consideraram-se duas situaçôes: com o número final de folhas (NFF) independentemente do número de ramificaçôes simpodiais e com um NF de 35 folhas para eliminar o efeito genotípico, já que as cultivares que não ramificaram produziram mais de cem folhas enquanto que as cultivares que mais ramificaram produziram no máximo de 35 a 40 folhas.

Foi calculado o balanço hídrico mensal pelo método de Thornthwaite \& Mather (1955), no qual a evapotranspiração de referência (Eto) é estimada pela temperatura média mensal, e foi considerada como capacidade de água disponível (CAD) $100 \mathrm{~mm}$. Os dados de temperatura média do ar $\left({ }^{\circ} \mathrm{C}\right)$ e de precipitação diários foram coletados na Estação Climatológica Principal da UFSM.
$\mathrm{Na}$ colheita, a produtividade $\left(\mathrm{t} \mathrm{ha}^{-1}\right) \mathrm{em}$ cada parcela foi determinada por amostragem das seis plantas marcadas da parcela. Os componentes de produtividade foram: massa fresca de raiz comercial e náo comercial $\left(\mathrm{t} \mathrm{ha}^{-1}\right)$, número de raízes comerciais e não comerciais por planta, massa fresca de hastes $\left(\mathrm{t} \mathrm{ha}^{-1}\right)$. Uma raiz foi considerada comercial quando apresentava diâmetro maior ou igual a $2 \mathrm{~cm}$ e $10 \mathrm{~cm}$ de comprimento, aquelas com dimensôes inferiores foram consideradas náo comerciais. No final de cada experimento também foi avaliada a altura da planta do solo até a primeira ramificação simpodial e a altura total, do solo até o ápice da planta.

Os dados foram submetidos à análise de variância e as médias foram comparadas pelo teste de Tukey $(\mathrm{p}<0,05)$ através do software estatístico SAS (SAS, 2002).

\section{RESULTADOS E DISCUSSÃO}

As equaçôes para cálculo da área de folhas individuais a partir do comprimento do folíolo central de cada cultivar estão na figura 1. Cada cultivar apresenta diferentes formatos de folha, o que resultou em coeficientes diferentes. A evolução do IAF das cultivares nos anos agrícolas 2010-2011 e 2011-2012 está na figura 2. As cultivares Fepagro-RS13 e Fepagro-RS14 tiveram o maior IAF máximo (de 8 a 10) comparado ao das cultivares Cascuda, Fécula Branca e Estrangeira. A diferença entre esses dois grupos de cultivares é a quantidade de ramificaçôes simpodiais, que nas cultivares Fepagro-RS13 e Fepagro-RS14 chega até a terceira ramificação simpodial, enquanto as outras culticares tiveram apenas a primeira e/ou segunda ramificação simpodial durante a estação de crescimento. O decréscimo do IAF das cultivares a partir do IAFmax foi devido à senescência das folhas, processo esse que se intensificou a partir dos 150 dias após a emergência. Essa senescência ocorre devido à diminuição da temperatura e do autossombreamento das folhas no interior do dossel (Gabriel et al., 2014).

Houve interação significativa entre cultivares e anos agrícolas para as variáveis filocrono da $\mathrm{HP}$, assim como no NFF da RS1 das cultivares Fepagro-RS13, Fepagro-RS14 e Cascuda, e por isso a análise estatística foi desdobrada (Tabela 2). Para as demais variáveis de crescimento, desenvolvimento e produtividade de hastes, como não houve interação significativa entre os valores dessas variáveis e anos agrícolas, a análise estatística não foi desdobrada (Tabela 3).

Para a variável filocrono considerando todas as folhas na haste principal, no ano agrícola 2010-2011 não houve diferença estatística entre as cultivares (Tabela 2, comparação na horizontal). Já em 2011-2012, a cultivar Fécula Branca foi a que apresentou maior valor de filocrono $\left(16,6^{\circ} \mathrm{C}\right.$ dia folha $\left.^{-1}\right)$, não diferindo das cultivares Cascuda, Fepagro-RS13 e Estrangeira. A cultivar que apresentou menor valor de filocrono foi a Fepagro-RS14 $\left(14,15^{\circ} \mathrm{C}\right.$ dia folha $\left.{ }^{-1}\right)$, porém não diferiu de 
Fepagro-RS13 e Estrangeira. As cultivares Fepagro-RS13 e Cascuda foram as únicas que apresentaram diferença estatística entre os anos agrícolas para filocrono da haste principal com NFF, sendo que seus valores de filocrono foram maiores no segundo experimento (Tabela 2, comparação na vertical). Comparando-se as cultivares como se todas tivessem o mesmo número de folhas final na haste principal (35 folhas), ficou mais evidente e diferente estatisticamente o maior filocrono
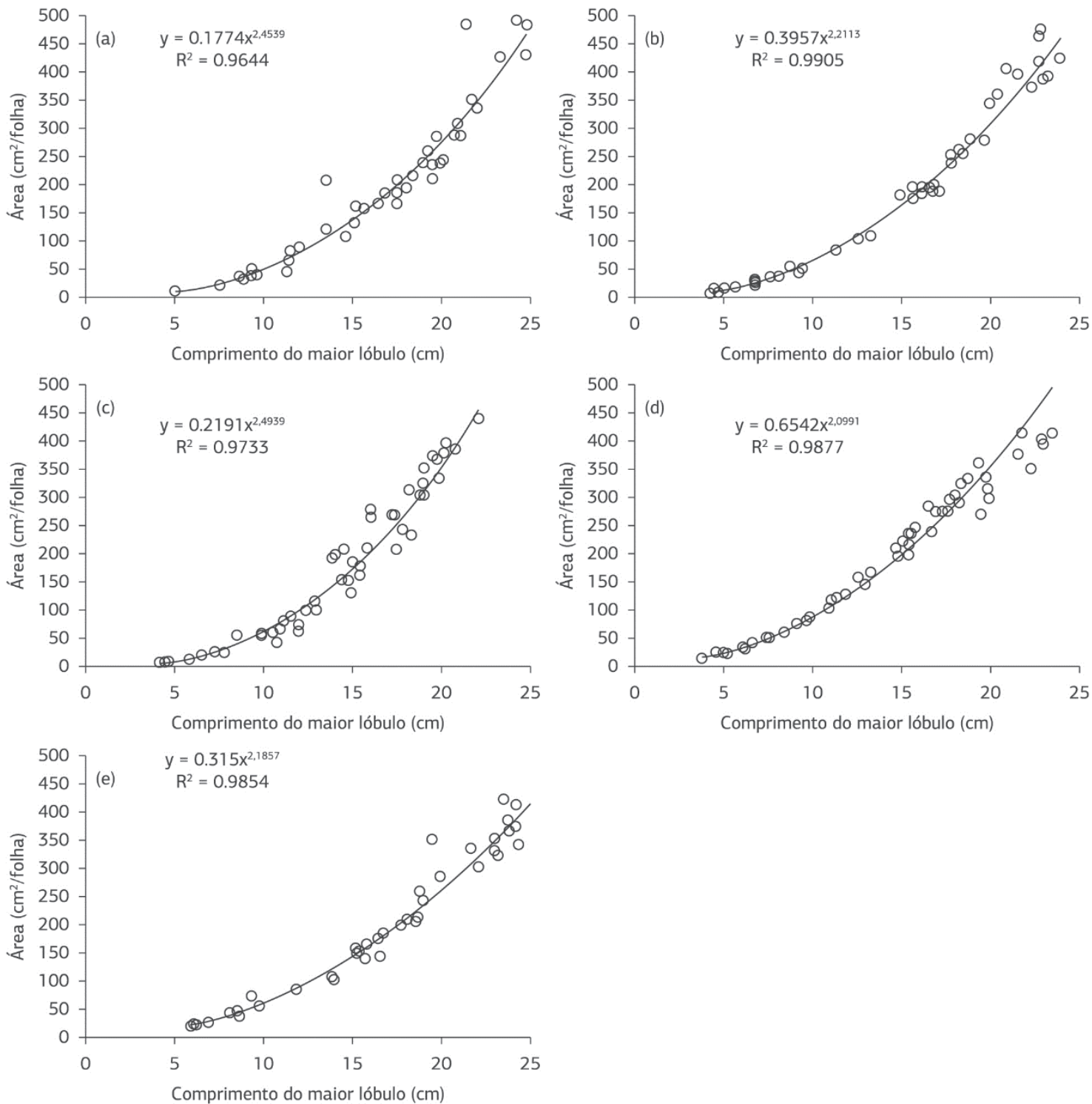

Figura 1. Equaçôes para cálculo da área de folhas individuais em função do comprimento do maior lóbulo nas cultivares de mandioca: (a) Fepagro-RS13, (b) Fepagro-RS14, (c) Fécula Branca, (d) Estrangeira e (e) Cascuda, em Santa Maria, RS, Brasil.

Tabela 2. Filocrono $\left({ }^{\circ} \mathrm{C}\right.$ dia folha $\left.{ }^{-1}\right)$ para a haste principal (HP) considerando o número de folhas (NF) na HP observada a campo nas cinco cultivares de mandioca (média de 35 folhas) e número final de folhas da primeira ramificação simpodial (NFFRS1) da RS1 nos anos agrícolas 2010-2011 e 2011-2012, em Santa Maria, RS, Brasil

\begin{tabular}{|c|c|c|c|c|c|}
\hline \multirow[t]{2}{*}{ Anos agrícolas } & \multicolumn{5}{|c|}{ Cultivares } \\
\hline & Fepagro-RS13 & Fepagro-RS14 & Cascuda & Estrangeira & Féc. Branca \\
\hline & \multicolumn{5}{|c|}{ Filocrono da haste principal com NFF $\left({ }^{\circ} \mathrm{C}\right.$ dia folha $\left.{ }^{-1}\right)$} \\
\hline 2010-2011 & $14,41 \mathrm{bA}^{*}$ & $13,87 \mathrm{aA}$ & $12,95 \mathrm{bA}$ & $14,80 \mathrm{aA}$ & $14,77 \mathrm{aA}$ \\
\hline \multirow[t]{2}{*}{ 2011-2012 } & $15,83 \mathrm{aAB}$ & $14,15 a B$ & $16,55 \mathrm{aA}$ & $15,62 \mathrm{aAB}$ & $16,60 \mathrm{aA}$ \\
\hline & \multicolumn{5}{|c|}{ NFFRS1 $\left({ }^{\circ} \mathrm{C}\right.$ dia folha-1 $)$} \\
\hline $2010-2011$ & $47,08 \mathrm{aA}$ & $40,97 \mathrm{aAB}$ & $39,74 \mathrm{aB}$ & - & - \\
\hline 2011-2012 & $31,75 \mathrm{bB}$ & $29,42 b C$ & $42,14 \mathrm{aA}$ & - & - \\
\hline
\end{tabular}

*Médias seguidas pela mesma letra minúscula na vertical e maiúscula na horizontal nâo diferem pelo teste Tukey a $5 \%$ de probabilidade de erro. 
da cultivar Fécula Branca $\left(17,13{ }^{\circ} \mathrm{C}\right.$ dia folha $\left.{ }^{-1}\right)$, que não difere estatisticamente do da Cascuda $\left(16,12^{\circ} \mathrm{C}\right.$ dia folha $\left.{ }^{-1}\right)$, e o menor filocrono da cultivar Fepagro-RS14 $\left(14,18^{\circ} \mathrm{C}\right.$ dia folha $^{-1}$ ), que não diferiu do das cultivares Fepagro-RS13 e Estrangeira (Tabela 3).
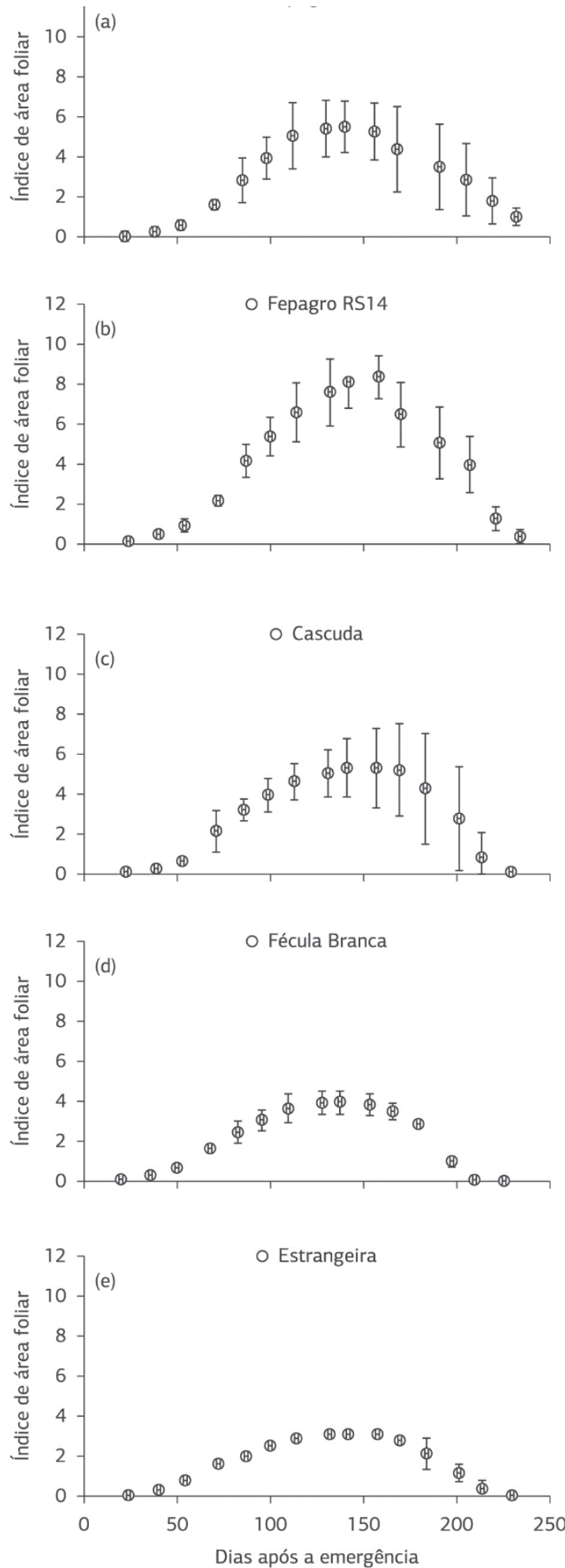

Os dois anos agrícolas foram classificados como anos de La Niña (NOAA, 2014), e em alguns meses durante a estação de crescimento, a precipitação foi abaixo da normal climatológica (Figuras 3c,d), e, entre os dois anos agrícolas, o que apresentou um período maior de tempo sem precipitação
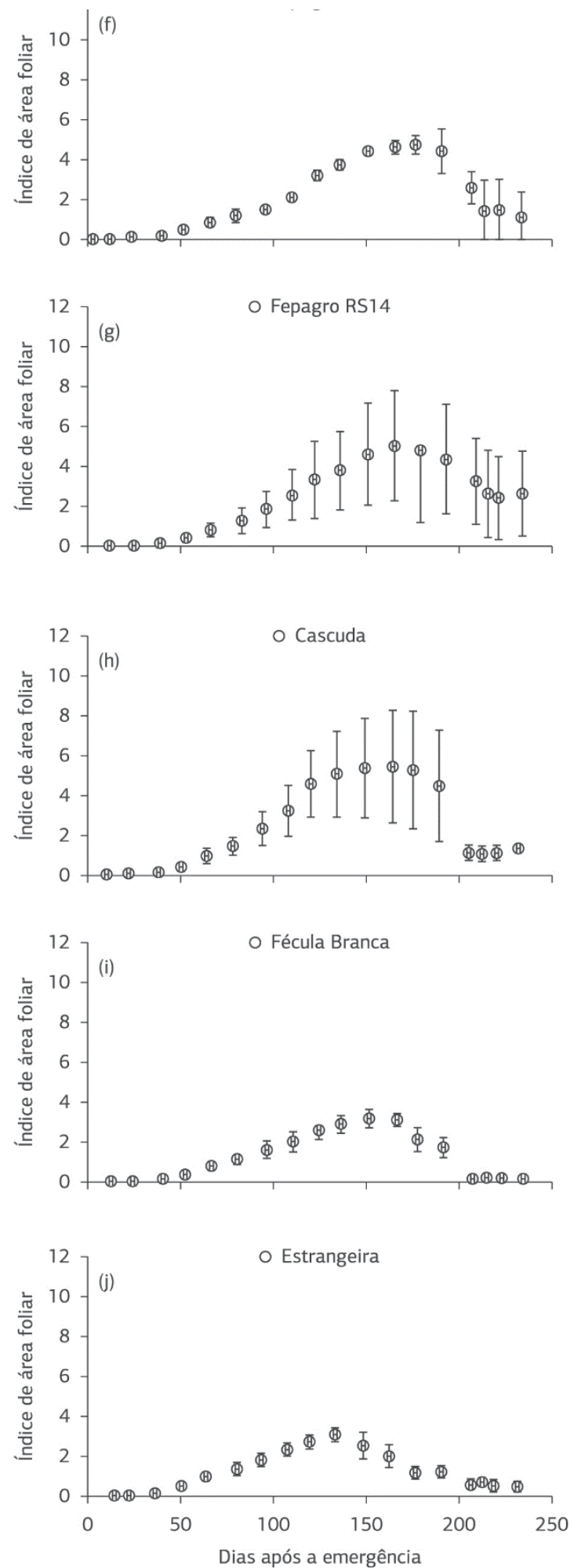

Figura 2. Evolução do índice de área foliar verde nas cultivares Fepagro-RS13, Fepagro-RS14, Estrangeira, Fécula Branca e Cascuda no experimento 2010-2011 (a, b, c, d, e) e no experimento 2011-2012 (f, g, h, i, j), em Santa Maria, RS, Brasil. 
foi o ano agrícola 2011-2012, com deficiência hídrica nos meses de novembro, dezembro e janeiro (Figura 3b). Essa deficiência hídrica pode ter contribuído para os maiores valores de filocrono no segundo ano e para a diferença entre anos nas cultivares Fepagro-RS13 e Cascuda (Tabela 2).

Comparando-se os valores de filocrono na HP entre as cultivares, aquelas que emitem mais ramificaçóes simpodiais, como Fepagro-RS13, Fepagro-RS14 e Cascuda acumularam menos folhas na HP (Tabela 3) e os valores de filocrono foram menores, ou seja, a velocidade de emissão de folhas na
HP foi maior (Tabelas 2, 3). Já naquelas que não emitiram ramificações simpodiais ou emitiram mais no final do ciclo, como as cultivares Estrangeira e Fécula Branca, os valores de filocrono foram maiores, ou seja, a velocidade de emissão de folhas foi menor. Nos anos agrícolas 2010-2011 e 2011-2012 não houve diferença estatística entre os valores de filocrono da RS1 nas cultivares (Tabela 3). Dentre os diferentes anos agrícolas, os valores de filocrono da RS1 foram maiores no segundo ano (Tabela 3).
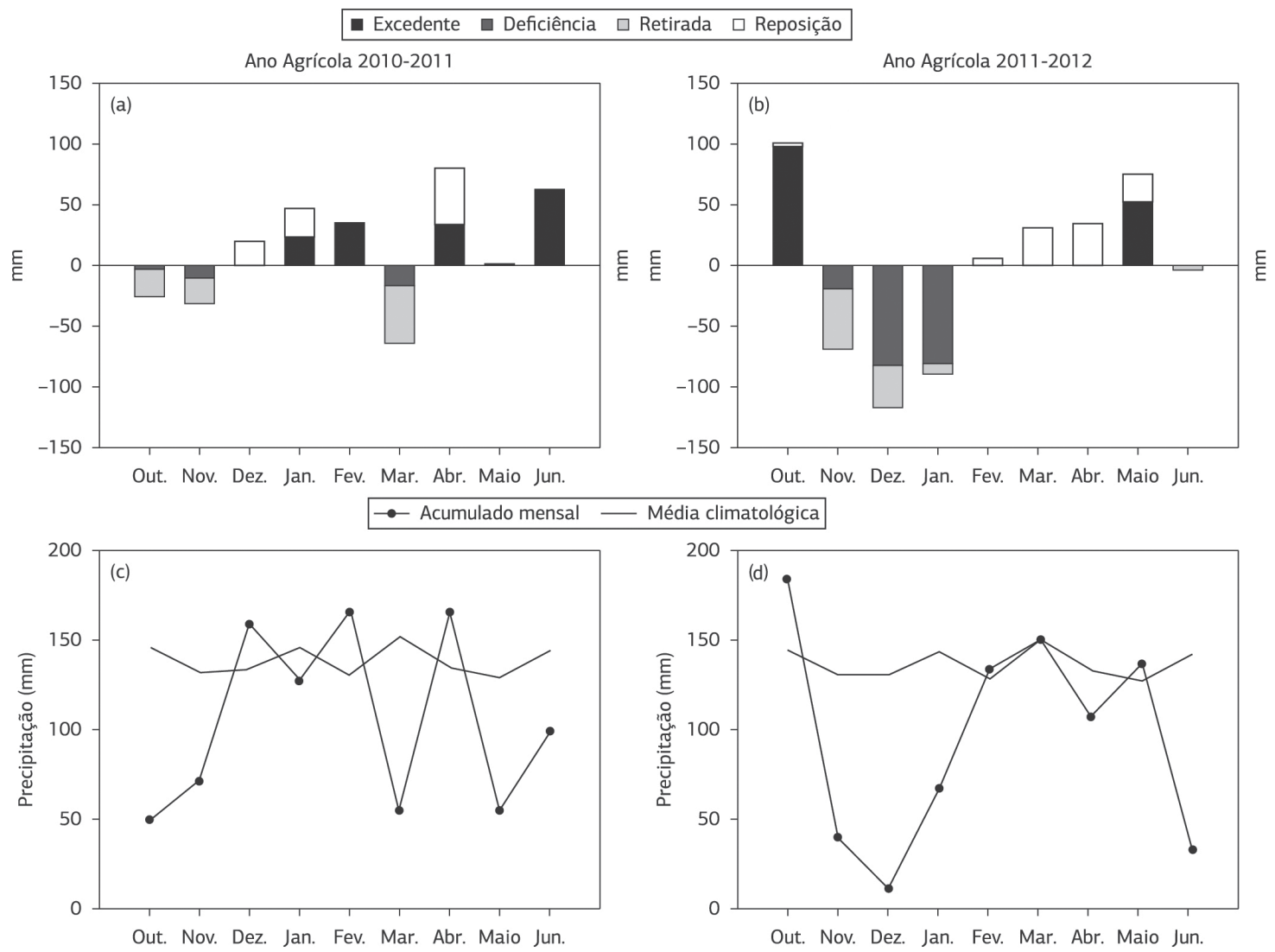

Figura 3. Balanço hídrico (a, b) e precipitaçáo acumulada mensal (c, d) durante a estação de crescimento da cultura da mandioca (outubro a junho) nos anos agrícolas 2010-2011 e 2011-2012, em Santa Maria, RS, Brasil.

Tabela 3. Filocrono para a primeira ramificação simpodial (FILO.RS1) para três cultivares de mandioca, altura total de planta (ALT.TOTAL), altura da primeira ramificação simpodial (ALT.RS1), massa fresca e seca de hastes (MFH e MSH), número final de folhas da haste principal (NFFHP) e filocrono ( ${ }^{\circ} \mathrm{C}$ dia folha ${ }^{-1}$ ) para a haste principal (HP), considerando que todas as cultivares ramificam com o mesmo NF médio (35 folhas), nos anos agrícolas 2010-2011 e 2011-2012, em Santa Maria, RS, Brasil

\begin{tabular}{|c|c|c|c|c|c|c|c|}
\hline $\begin{array}{l}\text { Cultivares ou } \\
\text { anos agrícolas }\end{array}$ & $\begin{array}{c}\text { FILO.RS1 } \\
\left({ }^{\circ} \mathrm{C} \text { dia folha }{ }^{-1}\right)\end{array}$ & $\begin{array}{l}\text { ALT. TOTAL } \\
(\mathrm{cm})\end{array}$ & $\begin{array}{l}\text { ALT.RS1 } \\
\text { (cm) }\end{array}$ & $\begin{array}{c}\text { MFH } \\
\left(t \text { ha }^{-1}\right)\end{array}$ & $\begin{array}{c}\text { MSH } \\
\left(\mathrm{t} \mathrm{ha}^{-1}\right)\end{array}$ & NFF HP & $\begin{array}{c}\text { FILO.HP } \\
\text { Com NF = } 35 \\
\left({ }^{\circ} \mathrm{C} \text { dia folha }{ }^{-1}\right)\end{array}$ \\
\hline Fepagro-RS13 & $18,42 a^{*}$ & $222,90 \mathrm{a}$ & $59,32 \mathrm{c}$ & $21,80 a$ & $5,87 \mathrm{a}$ & $40,74 d$ & $15,14 b c$ \\
\hline Fepagro-RS14 & $18,40 \mathrm{a}$ & $219,35 a$ & $61,69 \mathrm{c}$ & $20,31 \mathrm{a}$ & $5,56 a$ & $40,95 d$ & $14,18 \mathrm{C}$ \\
\hline Cascuda & $19,67 \mathrm{a}$ & $149,16 b$ & $75,16 \mathrm{c}$ & $13,87 b$ & $3,24 b$ & $52,61 \mathrm{c}$ & $16,12 a b$ \\
\hline Fécula Branca & - & $143,61 \mathrm{~b}$ & $119,73 \mathrm{~b}$ & $9,11 \mathrm{c}$ & $2,45 b$ & $98,77 b$ & $17,13 \mathrm{a}$ \\
\hline Estrangeira & - & $143,18 b$ & $139,68 \mathrm{a}$ & $8,22 \mathrm{c}$ & $2,12 b$ & $119,81 a$ & $15,20 \mathrm{bc}$ \\
\hline 2010-2011 & $16,98 \mathrm{~b}$ & $196,31 \mathrm{a}$ & $94,37 \mathrm{a}$ & $17,87 \mathrm{a}$ & $4,72 \mathrm{a}$ & $66,43 \mathrm{~b}$ & $14,70 \mathrm{~b}$ \\
\hline 2011-2012 & $20,68 a$ & $157,51 \mathrm{~b}$ & $86,59 a$ & $11,93 \mathrm{~b}$ & $3,11 b$ & $71,75 a$ & $16,25 \mathrm{a}$ \\
\hline
\end{tabular}

*Médias seguidas pela mesma letra minúscula na vertical náo diferem pelo teste Tukey a $5 \%$ de probabilidade de erro. 
Os valores de filocrono das cultivares que emitem mais ramificaçôes simpodiais, como Fepagro-RS13, Fepagro-RS14 e Cascuda, seguem a sequência HP $<$ RS1 (Tabela 2 e Tabela 3). O maior filocrono na RS1, que significa menor velocidade na emissão de folhas que na HP, pode ser explicado por essas plantas terem uma maior quantidade de drenos a partir de cada ramificação, pois a cada ramificação surgem de 2 a 4 novas hastes, dependendo da cultivar, reduzindo-se a velocidade de emissão de folhas na RS1. Esse aumento do filocrono a cada nova ramificação já havia sido verificado por Fagundes et al. (2009) para a cultivar Fepagro-RS13 e aqui confirmou-se esse resultado também para as cultivares Fepagro-RS14 e Cascuda.

Os maiores NFF na HP foram nas cultivares Estrangeira, seguido pela Fécula Branca e pela Cascuda, e os menores valores, nas cultivares Fepagro-RS13 e Fepagro-RS14 (Tabela 3). O NFF na RS1 diferiu estatisticamente entre as cultivares e entre os anos (Tabela 2), sendo que a cultivar Fepagro-RS13 apresentou maior NFF na RS1 no ano agrícola 2010-2011 e a cultivar Cascuda apresentou menor NFF, ambos não diferindo estatisticamente da cultivar Fepagro-RS14. No ano agrícola 2011-2012, a cultivar Cascuda apresentou maior NFF na RS1, diferindo estatisticamente das cultivares Fepagro-RS13 e Fepagro-RS14.

As alturas total da planta e até a primeira ramificação (RS1) apresentaram diferença estatística entre as cultivares, apresentando maior altura total as cultivares Fepagro-RS13 $(222,90 \mathrm{~cm})$ e Fepagro-RS14 $(219,35 \mathrm{~cm})$, e as menores, as cultivares Cascuda $(149,16 \mathrm{~cm})$, Fécula Branca $(143,61 \mathrm{~cm})$ e Estrangeira $(143,18 \mathrm{~cm})$. A maior altura até a RS1 foi nas cultivares que geralmente não ramificam, ou ramificam apenas no fim da estação de crescimento, como as cultivares Estrangeira (139,68 cm), seguida da Fécula Branca $(119,73 \mathrm{~cm})$, e a menor altura até a RS1 foi encontrada nas cultivares Cascuda $(75,16 \mathrm{~cm})$, Fepagro-RS14 $(61,69 \mathrm{~cm})$ e Fepagro-RS13 $(59,32 \mathrm{~cm}$ ) (Tabela 3). Entre os anos agrícolas, as cultivares apresentaram diferença estatística para altura total, com menor valor no ano 2011-2012, possivelmente devido à deficiência hídrica nos meses de novembro, dezembro e janeiro (Figura 3b).
Quanto à massa fresca e seca de hastes (MFH e MSH), as cultivares Fepagro-RS13 e Fepagro-RS14 foram superiores às demais (Tabela 3), confirmando e justificando a classificação dessas duas cultivares como destinadas à forragem. Já as demais cultivares produziram menor quantidade de parte aérea. Houve diferença estatística entre os anos agrícolas, com uma menor produção de MFH e MSH no ano agrícola 2011-2012.

Houve interação entre cultivares e anos agrícolas para as variáveis produtividade de raízes tuberosas $\left(\mathrm{tha}^{-1}\right)$ e peso de raízes comerciais (g), assim a análise estatística foi desdobrada para essas variáveis (Tabela 4). Para os demais componentes de produtividade de raízes não houve interação, por isso a análise não foi desdobrada (Tabela 5). A produtividade de raízes comerciais no ano agrícola 2010-2011 (primeiro experimento) variou de 20,4 t a 32,8 $\mathrm{t} \mathrm{ha}^{-1}$ (Tabela 3), sendo que as cultivares Fepagro-RS13, Fepagro-RS14, Cascuda e Estrangeira foram as que apresentaram maior produtividade e em 2011-2012 (segundo experimento), a qual variou de 25,3 t a 29,2 tha $^{-1}$, não ocorrendo diferença estatística entre as cinco cultivares. Comparando-se a produtividade das cultivares nos diferentes anos agrícolas, só houve diferença significativa para a cultivar Fepagro-RS14, que foi mais produtiva no primeiro ano, e para a cultivar Fécula Branca, que foi mais produtiva no segundo ano (Tabela 4).

Para a variável peso individual de raízes comerciais, no primeiro e segundo anos agrícolas, a cultivar Estrangeira foi a que apresentou maior peso de raízes comerciais $(251,6 \mathrm{~g}$ e $289,7 \mathrm{~g}$, respectivamente). No primeiro ano, ela náo diferiu estatisticamente das cultivares Fepagro-RS13 e Fepagro-RS14 (Tabela 4). A cultivar Fécula Branca foi a que apresentou menor peso de raízes comerciais $(185,6 \mathrm{~g})$, porém não diferiu das cultivares Cascuda, Fepagro-RS13 e Fepagro-RS14. Já no segundo ano, o maior peso de raízes comerciais apresentado pela cultivar Estrangeira náo diferiu estatisticamente das cultivares Fécula Branca, Fepagro-RS13 e Cascuda, e a cultivar Fepagro-RS14 foi a que apresentou menor peso de raízes comerciais $(212,1 \mathrm{~g})$, não diferindo das cultivares Cascuda e Fepagro-RS13 (Tabela 4).

As variáveis massa fresca de raízes não comerciais (MFRNC), número de raízes não comerciais (NRNC), peso de raízes

Tabela 4. Produtividade de raízes tuberosas $\left(\mathrm{t} \mathrm{ha}^{-1}\right)$ e peso de raízes comerciais (g) de cinco cultivares de mandioca em dois anos agrícolas, em Santa Maria, RS, Brasil

\begin{tabular}{|c|c|c|c|c|c|}
\hline \multirow{2}{*}{ Anos agrícolas } & \multicolumn{5}{|c|}{ Cultivares } \\
\hline & Fepagro-RS13 & Fepagro-RS 14 & Cascuda & Estrangeira & Féc. Branca \\
\hline & \multicolumn{5}{|c|}{ Produtividade de raízes tuberosas ( $\mathrm{t} \mathrm{ha}^{-1}$ ) } \\
\hline 2010-2011 & $32,83 \mathrm{aA}^{*}$ & $31,02 \mathrm{aA}$ & $28,70 \mathrm{aA}$ & $30,19 \mathrm{aA}$ & $20,40 \mathrm{bB}$ \\
\hline \multirow[t]{2}{*}{$2011-2012$} & 29,23 aA & 25,27 bA & $28,23 \mathrm{aA}$ & $26,90 \mathrm{aA}$ & 28,73 aA \\
\hline & \multicolumn{5}{|c|}{ Peso individual de raízes comerciais (g) } \\
\hline $2010-2011$ & 226,44 aAB & $212,85 \mathrm{aAB}$ & 202,96 aB & $251,61 \mathrm{aA}$ & 185,56 bB \\
\hline $2011-2012$ & $243,26 \mathrm{aAB}$ & $212,07 \mathrm{aB}$ & $232,57 \mathrm{aAB}$ & 289,72 aA & $284,69 \mathrm{aA}$ \\
\hline
\end{tabular}

*Médias seguidas pela mesma letra minúscula na vertical e maiúscula na horizontal não diferem pelo teste Tukey a $5 \%$ de probabilidade de erro. 
Tabela 5. Produtividade de massa fresca de raízes não comerciais (MFRNC), número de raízes comerciais e de raízes não comerciais (NRC e NRNC), peso de raízes não comerciais (PRNC) e massa seca de raízes comerciais e não comerciais (MSRC e MSRNC) de cinco cultivares de mandioca nos anos agrícolas 2010-2011 e 2011-2012, em Santa Maria, RS, Brasil

\begin{tabular}{|c|c|c|c|c|c|c|}
\hline $\begin{array}{l}\text { Cultivares ou } \\
\text { anos agrícolas }\end{array}$ & $\begin{array}{l}\text { MFRNC } \\
\left(\text { t ha-1) }^{-1}\right.\end{array}$ & NRC & NRNC & $\begin{array}{l}\text { PRNC } \\
\text { (g) }\end{array}$ & $\begin{array}{l}\text { MSRC } \\
\left(\mathrm{t} \mathrm{ha}^{-1}\right)\end{array}$ & $\begin{array}{r}\text { MSRNC } \\
\left(\mathrm{t} \mathrm{ha}^{-1}\right)\end{array}$ \\
\hline Fepagro-RS13 & $0,84 a^{*}$ & $8,46 \mathrm{a}$ & $2,31 \mathrm{a}$ & $23,08 \mathrm{a}$ & $11,75 a$ & $0,31 \mathrm{a}$ \\
\hline Fepagro-RS14 & $1,05 \mathrm{a}$ & $8,53 \mathrm{a}$ & $2,67 \mathrm{a}$ & 25,09 a & $10,52 a b$ & $0,40 \mathrm{a}$ \\
\hline Cascuda & $0,96 \mathrm{a}$ & $8,41 \mathrm{a}$ & $2,84 \mathrm{a}$ & $26,84 \mathrm{a}$ & $10,50 a b$ & $0,44 a$ \\
\hline Estrangeira & $0,89 a$ & $6,83 \mathrm{~b}$ & $2,82 \mathrm{a}$ & $21,86 a$ & $10,85 a b$ & $0,35 a$ \\
\hline Fécula Branca & $0,95 \mathrm{a}$ & $6,75 b$ & $2,29 a$ & $26,67 \mathrm{a}$ & $8,03 \mathrm{~b}$ & $0,38 a$ \\
\hline 2010/2011 & $0,94 \mathrm{a}$ & $8,57 \mathrm{a}$ & $2,55 \mathrm{a}$ & $25,64 \mathrm{a}$ & $11,09 a$ & $0,45 a$ \\
\hline $2011 / 2012$ & $0,93 \mathrm{a}$ & $7,11 \mathrm{~b}$ & $2,65 \mathrm{a}$ & $23,56 \mathrm{a}$ & $9,73 \mathrm{a}$ & $0,31 \mathrm{~b}$ \\
\hline
\end{tabular}

*Médias seguidas pela mesma letra minúscula na vertical não diferem pelo teste Tukey a $5 \%$ de probabilidade de erro.

não comerciais (PRNC) não variaram entre os genótipos e entre as diferentes datas de plantio (Tabela 5). As cultivares Fepagro-RS13, Fepagro-RS14 e Cascuda foram as que apresentaram maior número de raízes comerciais (NRC), comparados aos das cultivares Fécula Branca e Estrangeira. Analisando-se os dados dessa variável para os diferentes anos agrícolas, o NRC foi maior no primeiro ano (Tabela 5).

Em um experimento conduzido em Mato Grosso do Sul, Otsubo et al. (2009) encontraram produtividade de $12,5 \mathrm{t} \mathrm{ha}^{-1}$ de parte aérea e de $47 \mathrm{t} \mathrm{ha}^{-1}$ de raízes para a cultivar Fécula Branca, sendo o último valor bem acima do encontrado neste estudo. Isso ocorreu devido às condiçóes meteorológicas na região tropical serem bem mais favoráveis ao crescimento e desenvolvimento da cultura da mandioca que na regiáo subtropical. Ainda para essa mesma cultivar, Vidigal Filho et al. (2000), em experimento durante três estaçóes de crescimento no estado do Paraná, obtiveram uma produção média que variou de $10,11 \mathrm{ta} 15,64 \mathrm{t} \mathrm{ha}^{-1} \mathrm{e}$ 28,11 t a $30,2 \mathrm{t} \mathrm{ha}^{-1}$ da parte aérea e de raízes tuberosas, respectivamente, semelhantes às obtidas nesse estudo.

As cultivares Fepagro-RS13 e Fepagro-RS14, além de produzirem maior quantidade de parte aérea que as cultivares Fécula Branca, Cascuda e Estrangeira, também possuem elevada produçáo de raízes tuberosas (Tabelas 4 e 5). Isso indica que essas duas cultivares podem ser consideradas de duplo propósito (produção de parte aérea e de raízes), com boa adaptação às condiçóes de cultivo em ambiente subtropical no Rio Grande do Sul (Chielle et al., 2007, 2009) e, portanto, são boas opçóes para o agricultor familiar gaúcho. Já as cultivares Cascuda, Estrangeira e Fécula Branca possuem maior aptidão para produção de raízes tuberosas. A diferença entre esses dois grupos de cultivares é a quantidade de ramificaçóes simpodiais, que nas cultivares Fepagro-RS13 e Fepagro-RS14 chega até a terceira e/ou quarta ramificação simpodial e nas outras chega a apenas a primeira e/ou segunda ramificação simpodial durante a estação de crescimento, nas regiôes aptas ao cultivo de mandioca no Rio Grande do Sul.

\section{CONCLUSÃO}

As cultivares Fepagro-RS13 e Fepagro-RS14 possuem maior IAF com elevada produçáo de parte aérea e maior altura total comparada às cultivares Cascuda, Fécula Branca e Estrangeira por emitirem maior quantidade de ramificaçôes simpodiais, o que influencia também a velocidade de emissão de folhas na HP e RS1 e, consequentemente, os valores de filocrono. As cultivares Fepagro-RS13 e Fepagro-RS14 possuem elevada produção tanto de parte aérea quanto de raiz, enquanto as cultivares Cascuda, Estrangeira e Fécula Branca possuem maior aptidão para produçáo de raízes tuberosas em ambiente subtropical no Rio Grande do Sul, Brasil.

\section{REFERÊNCIAS}

Alves, A. A. C. Cassava botany and physiology. In R. J. Hillocks, J. M. Thresh, \& A. C. Bellotti. Cassava: biology, production and utilization (p. 67-89). Oxon, UK: CABI Publishing, 2002. Recuperado em 13 de março de 2012. de http://betuco.be/manioc/Cassava\%20-\%20 Botany\%20and\%20Physiology\%20cabi_08ch5.pdf

Cardoso, C. E. L., Souza, J. S., \& Gameiro, A. H. (2006). Aspectos econômicos e mercado. In Empresa Brasileira de Pesquisa Agropecuária - EMBRAPA. Aspectos socioeconômicos e agronômicos da mandioca (Cap. 2, p. 41-70). Cruz das Almas, BA: EMBRAPA Mandioca e Fruticultura Tropical.

Carvalho, J. E., \& Fukuda, W. M. G. (2006). Estrutura da planta e morfologia. In Empresa Brasileira de Pesquisa Agropecuária EMBRAPA. Aspectos socioeconômicos e agronômicos da mandioca (Cap. 6, p. 126-137). Cruz das Almas, BA: EMBRAPA Mandioca e Fruticultura Tropical.

Chielle, Z. G., Morales, C. F. G., \& Becker, L. (2007). Desempenho agronômico em $1^{\circ}$ e $2^{\circ}$ ciclos de cultivares de mandioca em Vera Cruz, RS. Revista Raízes e Amidos Tropicais, 3, 136-140.

Chielle, Z. G., Morales, C. F. G., Dornelles, M. A., Teixeira, C. D., \& Becker, L. (2009). Desempenho agronômico de cultivares e seleçôes de mandioca em Rio Pardo, RS. Pesquisa Agropecuária Gaúcha, 15, 53-56. 
Cock, J. H. (1990). La yuca: nuevo potencial para un cultivo tradicional. Cali: Centro Internacional de Agricultura Tropical.

Comissáo de Química e Fertilidade do Solo - CQFSRS. (2004). Manual de adubaçáo e calagem para os Estados do Rio Grande do Sul e de Santa Catarina (10. ed.). Porto Alegre: Sociedade Brasileira de Ciência do Solo, 2004.

Fagundes, L. K., Streck, N. A., Lopes, S. J., Rosa, H. T. R., Walter, L. C., \& Zanon, A. J. (2009). Desenvolvimento vegetativo em diferentes hastes da planta de mandioca em função da época de plantio. Ciência Rural, 39, 657-663. http://dx.doi.org/10.1590/ S0103-84782008005000097.

Food and Agriculture Organization of the United Nations - FAOSTAT. (2014). Production, crops. Recuperado em 27 de agosto de 2014, de http://faostat.fao.org/site/339/default.aspx.

Gabriel, L. F., Streck, N. A., Roberti, D. R., Chielle, Z. G., Uhlmann, L. O., Silva, M. R., \& Silva, S. D. (2014). Simulating cassava growth and yield under potential conditions in Southern Brazil. Agronomy Journal, 106, 1119-1137. http://dx.doi.org/10.2134/agronj2013.0187.

Instituto Brasileiro de Geografia e Estatística - IBGE. (2014). Dados de previsão de safra: mandioca. Recuperado em 27 de agosto de 2014, de http://www.sidra.ibge.gov.br/bda/prevsaf/.

Morales, C. F. G., Chielle, Z. G., Dornelles, M., Teixeira, C. D., \& Coutinho, A. (2009). Avaliação de cultivares e seleçóes de mandioca (Manihot esculenta Crantz) no município de Rio Pardo, Rio Grande do Sul, 2008-2009. Revista Raízes e Amidos Tropicais, 5, 230-234.

National Oceanic and Atmospheric Administration - NOAA. (2014). ENSO: cold and warm episodes by season. Washington: NOAA. Recuperado em 29 de março de 2014, de http://www.cpc.noaa.gov/ products/analysis_monitoring/insostuff/ensoyears.shtml.
Otsubo, A. A., Brito, O. R., Mercante, F. M., Otsubo, V. H. N., Gonçalves, M. A., \& Telles, T. S. (2009). Desempenho de cultivares elites de mandioca industrial em área de cerrado do Mato Grosso do Sul. Semina. Ciências Agrárias, 30, 1155-1162. http://dx.doi. org/10.5433/1679-0359.2009v30n4Sup1p1155.

Statistical Analysis System - SAS. (2002). Getting started with the $\mathrm{SAS}^{\circledast}$ learning edition. Cary, NC: SAS Institute.

Schons, A., Streck, N. A., Kraulich, B., Pinheiro, D. G., \& Zanon, A. J. (2007). Emissão de folhas e início de acumulação de amido em raízes de uma variedade de mandioca em função da época de plantio. Ciência Rural, 37, 1586-1592. http://dx.doi.org/10.1590/ S0103-84782007000600013.

Schons, A., Streck, N. A., Storck, L., Buriol, G. A., Zanon, A. J., Pinheiro, D. G., \& Kraulich, B. (2009). Arranjos de plantas de mandioca e milho em cultivo solteiro e consorciado: crescimento, desenvolvimento e produtividade. Bragantia, 68, 165-177. http:// dx.doi.org/10.1590/S0006-87052009000100017.

Thornthwaite, C. W., \& Mather, J. R. (1955). The waterbalance. Publications in Climatology, 3, 1-104.

Vidigal Filho, P. S., Pequeno, M. G., Scapim, C. A., Vidigal, M. C. G., Maia, R. R., Sagrilo, E., Simon, G. A., \& Lima, R. S. (2000). Avaliação de cultivares de mandioca na região noroeste do Paraná. Bragantia, 59, 69-75. http://dx.doi.org/10.1590/S0006-87052000000100011.

Wilhelm, W. W., \& McMaster, G. S. (1995). Importance of the phyllochron in studying development and growth in grasses. Crop Science, 35, 1-3. Recuperado em http://digitalcommons.unl.edu/ usdaarsfacpub/85. http://dx.doi.org/10.2135/cropsci1995.001118 3X003500010001x. 